\title{
Negative regulation of cyclin D3 expression by trans- cription factor c-Ets1 in umbilical cord hematopoietic cells
}

\author{
Fan-kai MENG, Han-ying SUN, Xi-you TAN ${ }^{\S}$, Chun-rui LI, Jian-feng ZHOU, Wen-li LIU* \\ Department of Hematology, Tongji Hospital, Tongji Medical College, Huazhong University of Science and Technology, Wuhan 430030, \\ China
}

Aim: To investigate the role of transcription factor c-Ets1 in cyclin D3 expression and its effects on the proliferation of umbilical cord hematopoietic cells.

Methods: Cyclin D3 promoter deletion constructs were generated and transfected into CD34 ${ }^{+}$cells. Dual luciferase reporter assays and TFSEARCH software were used to identify negative regulatory domains and to predict putative transcription factors involved in cyclin D3 downregulation. Expression of c-Ets1 in CD34 ${ }^{+}$cells was detected using electrophoretic mobility shift and super shift assays. Point mutants of c-Ets1 binding sites were constructed. The wild-type c-Ets1 and the mutant promoter constructs were co-transfected into $\mathrm{CD} 34^{+}$cells to determine the promoter activity. The impact of c-Ets 1 expression on the proliferation of CD34 ${ }^{+}$cells was assessed using MTT assay.

Results: Nine cyclin D3 promoter deletion constructs were generated. A negative regulatory domain containing c-Ets1 binding sites was identified between -439 bp and -362 bp. Transfection of the promoter deletion constructs containing mutant c-Ets 1 binding sites enhanced cyclin D3 promoter activity. However, the opposite results were observed when CD34 ${ }^{+}$cells were co-transfected with wildtype c-Ets1 and its promoter deletion constructs. The overexpression of c-Ets1 could suppress cyclin D3 mRNA and protein levels. In addition, it inhibits the proliferation of $\mathrm{CD} 34^{+}$cells.

Conclusion: c-Ets1 functions as a negative transcription factor, down-regulating the expression of cyclin D3, which leads to inhibition of CD34 ${ }^{+}$cell proliferation.

Keywords: transcription factor c-Ets1; cyclins; hematopoietic stem cells; CD34+ cells; gene regulation; cell cycle; point mutation

Acta Pharmacologica Sinica (2011) 32: 1159-1164; doi: 10.1038/aps.2011.41; published online 15 Aug 2011

\section{Introduction}

Hematopoiesis is a continuous process of blood production that begins with the self-renewal and differentiation of hematopoietic stem cells (HSCs). HSCs are mainly in a quiescent state; only small amounts of HSCs enter the cell cycle to proliferate and differentiate into mature blood cells. During this process, many regulators control the balance between cycling and quiescence as well as between proliferation and differentiation. When this balance is broken, hematological diseases result. One example of this is leukemia, whereby leukemic cells become transformed, gaining the ability to proliferate but losing the ability to effectively differentiate. The

\footnotetext{
$\S$ Now in Department of Bone Marrow Transplantation, Shanghai Daopei Hospital, Shanghai 200240, China.

*To whom correspondence should be addressed. E-mail liuwenlitj@163.com

Received 2010-12-24 Accepted 2011-04-13
}

molecular regulators of this balancing act are the subject of intense study in the field of hematopoiesis ${ }^{[1]}$.

The cell cycle is controlled by cyclins, cyclin-dependent kinases (CDKs) and CDK inhibitors. Cyclin D is the first cyclin expressed in the cell cycle after stimulation by mitogenic signals. The complex of cyclin D and CDK $4 / 6$ stimulates cells to enter the cell cycle and complete the $G_{1} / S$ phase transition. Once a cell passes this checkpoint, the cell can go through the whole cell cycle and division irrevocably ${ }^{[2,3]}$. Cyclin $E$ is the other cyclin involved in the $G_{1} / S$ phase transition. However, constitutive expression of cyclin E2 cannot bypass arrest at the $\mathrm{G}_{1}$ phase induced by cyclin D1 degradation ${ }^{[4]}$. This indicates that cyclin D is the most important cyclin in the cell cycle. The dominant isoform, cyclin D3, is uniquely required for the proliferation of HSCs and is regulated mainly at the transcriptional level in these cells ${ }^{[2,5]}$. Transcription factors bind to the promoter of cyclin D3, regulating the expression of the cyclin 
D3 gene. Both positive and negative regulators could theoretically be involved in this regulation ${ }^{[6]}$. However, most studies have focused on the positive regulators, with characterization of negative regulators seldom reported in the literature.

The transcription factor c-Ets1 is a member of the Ets family of transcription factors, commonly involved in the regulation of development, differentiation and proliferation ${ }^{[7]}$. c-Ets1 is expressed in hematopoietic cells and contributes to their cellular differentiation. It plays an essential role in lymphoid cell differentiation and also promotes megakaryocytic and early erythroid differentiation ${ }^{[8-12]}$. In general, the proliferative ability of hematopoietic cells declines along with the cell's differentiation to a more mature cell stage. Because c-Ets1 promotes differentiation, it may also limit the proliferation of hematopoietic cells. We found a negative regulatory region in the promoter of cyclin D3 and a c-Ets1-binding motif in this region. As previously discussed, c-Ets1 may play a negative role in the expression of cyclin D3.

Umbilical cord HSCs possess common characteristics of human HSCs and have the advantages of being easily procured with a low risk to donors. For these reasons, these cells have become an alternative source of HSCs for experimental and clinical studies ${ }^{[13]}$. In these experiments, umbilical cord HSCs were utilized to explore the underlying mechanism in the regulation of cyclin D3 by c-Ets1.

\section{Materials and methods Cell culture}

Human $\mathrm{CD}_{3} 4^{+}$cells were obtained from umbilical cord blood of healthy donors. CD $34^{+}$cells were isolated using MidiMACS technology (Miltenyi Biotec, Germany) according to the manufacturer's instructions. Briefly, $50 \mathrm{~mL}$ of umbilical cord blood was treated with Ficoll-Paque ${ }^{\mathrm{TM}}$ PLUS to isolate mononuclear cells. To prevent coagulation, $0.6 \%$ ACD-A was added. $\mathrm{CD} 34^{+}$cells were purified twice with the MidiMACS. The purified cells were seeded at $1 \times 10^{5}$ cells $/ \mathrm{mL}$ in 24-well plates and maintained in Iscove's modified Dulbecco's medium (IMDM) supplemented with $25 \%$ fetal bovine serum (FBS), penicillin (100 IU/mL), stem cell factor (SCF) $(100 \mathrm{ng} /$ $\mathrm{mL})$, FLt3-L (100 ng/mL), IL-3 (50 ng/mL), IL-6 (50 ng/mL) and thrombopoietin (TPO) $(2 \mathrm{U} / \mathrm{mL})$ in a humidified atmosphere at $5 \% \mathrm{CO}_{2}$ and $37{ }^{\circ} \mathrm{C}$. The medium was refreshed on the third day and cells were harvested on the sixth day. The harvested cells were utilized for all subsequent experiments. After harvesting, cells were stained with mouse anti-CD34FITC antibodies, with mouse $\operatorname{IgG}_{1}$ (BD Biosciences, USA) used as a negative control. Cells were incubated at $4^{\circ} \mathrm{C}$ in the dark for $30 \mathrm{~min}$, washed with PBS, fixed with $1 \%$ paraformaldehyde and subsequently analyzed by flow cytometry (Becton Dickinson, USA) to measure the proportion of $\mathrm{CD} 34^{+}$cells present. The results were obtained from three independent samples.

\section{Plasmid constructs}

To generate the cyclin D3 promoter deletion constructs, the restriction endonuclease sites of the full-length sequence of human cyclin D3 promoter were predicted by Webcutter 2.0 software. Using human blood lymphocyte genomic DNA as a template, cyclin D3 promoter deletions of different lengths were amplified by polymerase chain reaction (PCR). The primers utilized were as follows: sense primers (containing Kpn I sites) were:

PA1 (Kpn I -1042): 5'-CGG GGT ACC ggg agg tgg aag aaa $\operatorname{tg} \mathrm{C}-3^{\prime}$,

PA2 (Kpn I -924): 5'-CGG GGT ACC ggg ctt gtc caa acc tag-3',

PA3 (Kpn I -764): 5'-CGG GGT ACC gag agt ctg cat ttc taa CC-3',

PA4 (Kpn I -686): 5'-CGG GGT ACC ggt gta gaa cac aga atc $\operatorname{tg}-3^{\prime}$,

PA5 (Kpn I -549): 5'-CGG GGT ACC gca gcg ttc act aag aac-3',

PA6 (Kpn I -436): 5'-CGG GGT ACC att gtt tcc tgg gtg act ag-3',

PA7 (Kpn I -380): 5'-CGG GGT ACC aag ttc tct gca ccc ggt gg-3',

PA8 (Kpn I -262): 5'-CGG GGT ACC gct cag cca acc ctt tcc-3' and

PA9 (Kpn I -195): 5'-CGG GGT ACC att cca cgg ttg cta cat c-3';

and the antisense primer (containing Smal I sites) was PB $(\sim+2): 5^{\prime}$-TCC CCC GGG ata ctc ggg cag cga aca-3'.

PCR conditions (Table 1) varied according to expected product lengths. PCR fragments were inserted into pGEM-T Easy vectors (Promega, USA) between the Kpn I and Bam I sites. Subcloning of the amplified fragments into the luciferase expression vector pGL3-Basic (Promega, USA) was performed via Kpn I and $B g l$ II sites (Bam I and $B g l$ II sites are compatible). The constructs were designated as $\mathrm{pD} 3-\Delta$, where $\Delta$ refers to the number of base pairs in the upstream $5^{\prime}$-flanking sequence with respect to the start codon of cyclin D3.

Table 1. PCR conditions for application of various promoter deletion fragments.

\begin{tabular}{cllll}
\hline $\begin{array}{l}\text { Promoter } \\
\text { sequence }\end{array}$ & Denaturation & Anneal & Extension & Cycles \\
& & & & \\
\hline pA1B, pA2B & $94^{\circ} \mathrm{C} 1$ min & $55^{\circ} \mathrm{C}$ & $72^{\circ} \mathrm{C} 2$ min & 30 \\
pA3B & the first cycle 5 min & 1 min & the last cycle 8 min & \\
pA4B, pA5B & $94^{\circ} \mathrm{C} 1$ min & $56^{\circ} \mathrm{C}$ & $72^{\circ} \mathrm{C} 2$ min & 30 \\
pA6B & the first cycle 5 min & 1 min & the last cycle 8 min & \\
pA7B, pA8B & $94^{\circ} \mathrm{C} 1$ min & $56^{\circ} \mathrm{C}$ & $72^{\circ} \mathrm{C} 1$ min & 30 \\
pA9B & the first cycle 5 min & $45 \mathrm{~s}$ & the last cycle 8 min & \\
\hline
\end{tabular}

pA1B is the full-length promoter. Kpn I and Smal I sites are respectively included in sense and anti-sense primers.

\section{Liposomal transient transfection and luciferase assay}

The harvested cells $\left(5 \times 10^{5}\right.$ cells $\left./ \mathrm{mL}\right)$ were transiently transfected using Lipofectamine 2000 (Invitrogen, USA) according to the manufacturer's instructions. Briefly, cells were plated in 24-well plates in IMDM with 15\% FBS and transfected using 
$0.8 \mu \mathrm{g}$ of the luciferase reporter plasmid (pD3- $\Delta$ or pD3-Basic vector), with $0.1 \mathrm{ng}$ of $\mathrm{pRL}-\mathrm{CMV}$ as an internal control in each well. The cells were harvested $36 \mathrm{~h}$ later, and lysates were assayed with the dual luciferase reporter system (Promega, USA) on a SIRIUS Luminometer V3.1 (Berthold, Germany) to determine the promoter activity. The negative regulatory domain was identified based on the results from five independent experiments.

\section{Electrophoretic mobility shift assay (EMSA)}

c-Ets1 was selected as a candidate transcription factor that might bind the negative regulatory domain of cyclin D3 with the assistance of TFSEARCH 1.3v software ${ }^{[14]}$. Nuclear extracts were prepared to determine the expression of c-Ets1 in CD34 ${ }^{+}$ cells using an EMSA kit (Panomics, USA) according to the manufacturer's instructions. The DNA sequence of the c-Ets1 probe was 5'-GGA GGA GGG CTG CTT GAG GAA GTA TAA GAA T-3'. Nuclear extracts $(15 \mu \mathrm{g})$ were co-incubated with biotin-labeled specific DNA probes and c-Ets1 antibodies (Santa Cruz, CA), subjected to 6\% SDS-PAGE and transferred to membranes. Bands were visualized with ECL (Amersham, $\mathrm{UK})$.

\section{Point mutant constructs}

The core-binding motif of c-Ets1 is GAAG (CTTC on the antisense chain). To confirm that c-Ets1 could bind to the CTTC motif present in the cyclin D3 promoter, a point mutant construct was generated by PCR with primers P1 (5'-GGG AAG CTT TTT GCA AAA GCC TAG GCC TCC-3') and P2 (5'-TTT GGT ACC ATT GTT CTT CGG GTG ACT AGA GTC CGA GAA G-3'). Hind III and Kpn I restriction sites are underlined and were designed in order to convert the sequence TCCT to CTTC (dotted). Using human blood lymphocyte genomic DNA as a template, PCR was conducted as follows: $94^{\circ} \mathrm{C}$ for 5 min (first cycle), followed by 30 cycles of $94^{\circ} \mathrm{C}$ for $1 \mathrm{~min}, 55^{\circ} \mathrm{C}$ for $1 \mathrm{~min}$ and $72^{\circ} \mathrm{C}$ for $1 \mathrm{~min}$, followed by a final extension at $72^{\circ} \mathrm{C}$ for $10 \mathrm{~min}$. PCR products were inserted into pUcm-T vectors for amplification and sub-cloned into the pGL3-Basic vector. $\mathrm{CD} 34^{+}$cells were transfected either with a promoter construct or its corresponding mutant and incubated for $36 \mathrm{~h}$ before luciferase activity was determined.

\section{Western blot}

$\mathrm{CD}_{4} 4^{+}$cells were harvested $36 \mathrm{~h}$ after being transfected with either pSG5-Ets1 or pSG5 vectors. The pSG5-Ets1 expression vector was kindly provided by Prof J CHEN of Tzu Chi University, Taiwan, China. Total protein was extracted, subjected to SDS-PAGE, transferred to the membrane and successively incubated with cyclin D3 and $\beta$-actin (internal control) antibodies followed by corresponding secondary antibodies. Cyclin D3 and $\beta$-actin bands were visualized with ECL.

\section{RT-PCR}

$\mathrm{CD} 4^{+}$cells were harvested $36 \mathrm{~h}$ after transfection with either pSG5-Ets1 or pSG5 vectors. Semi-quantitative RT-PCR was employed to examine mRNA expression. The primers $5^{\prime}$-GAG GGG GAA TAG TCT AGA TG-3' (sense) and 5'-TAC AGT AGG ATG ATG GT CCT-3' (antisense) were utilized for the cyclin D3 gene (515 bp). The PCR conditions were as follows: $94^{\circ} \mathrm{C}$ for $5 \mathrm{~min}$ (first cycle), 28 cycles of $94^{\circ} \mathrm{C}$ for $1 \mathrm{~min}, 56^{\circ} \mathrm{C}$ for $1 \mathrm{~min}$ and $72^{\circ} \mathrm{C}$ for $1 \mathrm{~min}$, followed by a final extension at $72^{\circ} \mathrm{C}$ for $8 \mathrm{~min}$. For GAPDH (340 bp), the primers $5^{\prime}$-CCT TGC CTC TCA GAC AAT GC-3' (sense) and 5'-CCA CGA CAT ACT CAG CAC-3' (antisense) were used under the same PCR conditions. An aliquot of each reaction mixture was analyzed by electrophoresis on 1\% agarose gel, and the band density was determined.

\section{Methyl thiazolyl tetrazolium (MTT) assay}

$\mathrm{CD}_{4} 4^{+}$cells were separated into two groups and transfected with either pSG5-Ets1 or pSG5 vectors. The proliferation of these cells was determined by MTT (Sigma, USA) assay. The transfected cells were seeded into 96 -well plates $\left(5 \times 10^{3}\right.$ cells/ well) and incubated for $36 \mathrm{~h}$ in triplicate. Fifty microliters of MTT solution $(1 \mathrm{mg} / \mathrm{mL})$ was added to each well for $4 \mathrm{~h}$ at $37^{\circ} \mathrm{C}$. Subsequently, $100 \mu \mathrm{L}$ of DMSO (Sigma, USA) was added to each well for $10 \mathrm{~min}$ at $37^{\circ} \mathrm{C}$. Optical density $(O D)$ values of each well were measured in a microplate reader at $490 \mathrm{~nm}\left(A_{490}\right)$. The experiment was repeated three times.

\section{Statistical analysis}

Results are presented as the mean \pm standard deviation (SD). Student's $t$-test for paired data was used to determine significant differences between the two groups. Differences were considered significant when the $P$ value was less than 0.05 .

\section{Results}

\section{Isolation and confirmation of $\mathrm{CD} 34^{+}$cells}

Purification of $85.06 \% \pm 3.02 \%$ CD $34^{+}$cells was achieved from umbilical cord blood after two rounds of purification with Midi-MACS (Figure 1A). Additionally, $60 \% \pm 4.31 \%$ of cells were $\mathrm{CD} 34^{+}$after $6 \mathrm{~d}$ of culture and proliferation (Figure 1B).

\section{Construction of promoter deletion plasmids for cyclin D3}

Nine cyclin D3 promoter deletion fragments were generated by PCR and inserted into the pGL3-Basic vector $(\mathrm{pD} 3-\Delta)$ that contained the luciferase reporter gene. The results of restriction enzyme digestion patterns and nucleic acid sequencing confirmed the contents of the constructs.

\section{Promoter activity in $\mathrm{CD} 34^{+}$cells}

The $\mathrm{CD} 34^{+}$cells exhibited various levels of luciferase activity when transiently transfected with either pD3- $\Delta$ or pD3-Basic vectors. The relative activity of the promoter was defined as the ratio of the luciferase activity value of promoter deletion constructs (pD3- $\Delta$ ) to that of the complete promoter sequence (pD3-1044) (Figure 2). According to our results, the promoter activity of pD3-362 was greatly enhanced compared with that of pD3-439 $(P<0.01)$, which indicated that a negative regulatory sequence was located between $-439 \mathrm{bp}$ and $-362 \mathrm{bp}$. 

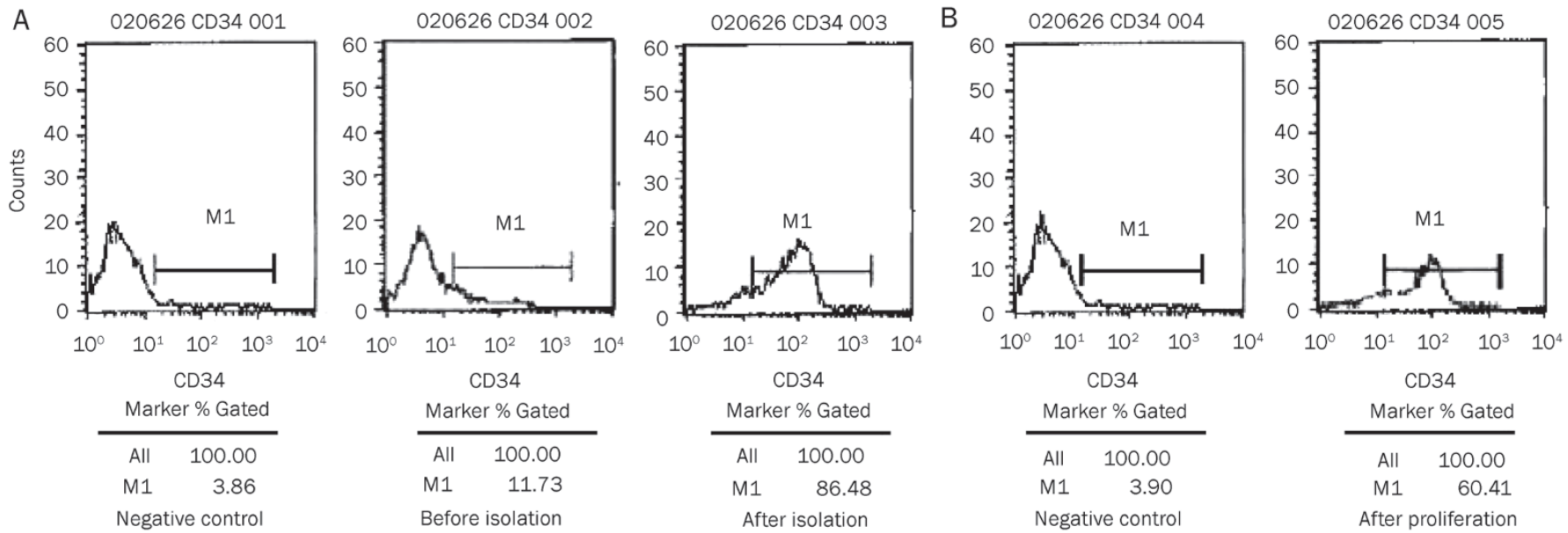

Figure 1. Flow cytometry analysis of $\mathrm{CD}_{3} 4^{+}$cells. Cells were isolated from umbilical cord blood and stained mouse anti-CD34-FITC antibody, with mouse IgG1 as negative control and analyzed with flow cytometry. (B) Proportion of CD34 ${ }^{+}$cells after a 6 -d proliferation.

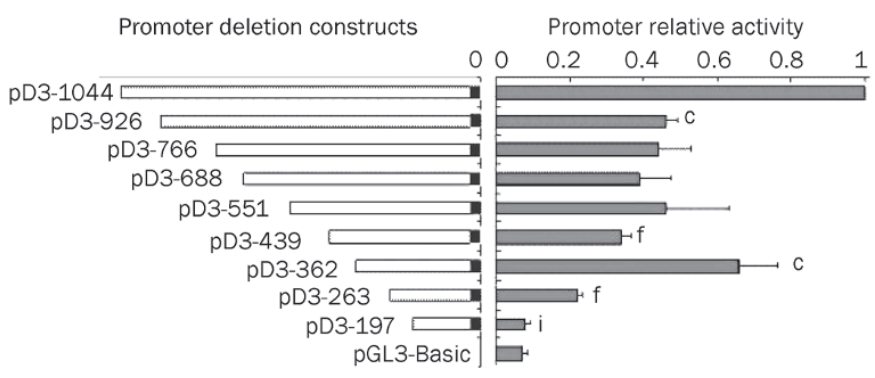

Figure 2. The function analysis of cyclin D3 promoter. CD34 ${ }^{+}$cells transfected with pD3- $\Delta$ or pD3-Basic were harvested $36 \mathrm{~h}$ later and lysates were subjected to Dual Luciferase reporter system to determine the promoter activity. $n=6$. Mean \pm SD. ${ }^{\mathrm{c}} P<0.01$ vs pD3-1044. ${ }^{\mathrm{e}} P<0.05$, ${ }^{f} P<0.01$ vs pD3-362. ' $P<0.01$ vs pD3-263.

c-Ets1 is a candidate to negatively regulate cyclin D3 transcription

Based on the results above, we utilized TFSEARCH 1.3 to search for transcription factor binding sites over the regulatory region between $-439 \mathrm{bp}$ and $-362 \mathrm{bp}$. We found binding sites for USF, c-Ets, HNF-3b, N-Myc and Lyf-1. Excluding putative transcriptional activators and those not involved in hematopoiesis, we speculated that c-Ets1, which was widely expressed in hematopoietic cells, was a good candidate involved in the negative regulation of cyclin $\mathrm{D} 3^{[5-11]}$. To test this hypothesis, we performed EMSA and super shift assays to determine the nuclear expression of c-Ets1 in $\mathrm{CD} 34^{+}$cells. As shown in Figure 3A, c-Ets1 was detected with specific oligonucleotide probes and antibodies, confirming that c-Ets1 was expressed in the nuclei of CD $34^{+}$cells.

c-Ets1 binds to an AGGA core sequence in the regulatory domain of cyclin D3

We generated the point mutant pD3-439m to further analyze the binding sites of c-Ets1 to the negative regulatory domain of the cyclin D3 promoter. The dual luciferase assay indicated that $\mathrm{pD} 3-439 \mathrm{~m}$ transfected cells had increased relative promoter activity $(0.58 \pm 0.06)$ compared with those transfected with wild-type pD3-439 (0.36 \pm 0.09$)$, with a $P$ value less than 0.05 . We speculate that c-Ets1 binds to the AGGA core sequence on the negative regulatory region.

\section{c-Ets1 expression suppresses the activity of the cyclin D3 promoter}

To further confirm the negative effects of c-Ets1 on cyclin D3 expression, $\mathrm{CD} 34^{+}$cells were transfected with the c-Ets1 expression plasmid pSG5-Ets1 or the empty vector pSG5. Western blot results confirmed that c-Ets1 was overexpressed in $\mathrm{CD}_{3} 4^{+}$cells after transfection (Figure 3B). Furthermore, we co-transfected the CD $34^{+}$cells with pSG5-Est1 (or pSG5) and the promoter deletion constructs pD3-1044, pD3-926, pD3-439, pD3-362, pD3-263 or pGL3-Basic. Luciferase assays indicated that c-Ets1 significantly inhibited the activity of pD3-1044, pD3-439 and pD3-362 transfected cells (Figure 3C) $(P<0.05)$, which confirmed that c-Ets1 was negatively regulating the cyclin D3 promoter.

\section{c-Ets1 suppresses cyclin D3 expression in CD $34^{+}$cells}

Finally, we investigated the effects of c-Ets1 on the expression of cyclin D3 in CD34 ${ }^{+}$cells. The expression of both cyclin D3 mRNA (Figure 4A) and protein levels (Figure 4B) was downregulated by overexpressing c-Ets1.

\section{c-Ets1 inhibits the proliferation of $\mathrm{CD} 34^{+}$cells}

Compared with the pSG5 vector group (1.623 \pm 0.086$)$, the $O D$ value of the pSG5-Ets1 group $(1.336 \pm 0.107)$ was lower $(P<0.05)$. The inhibition rate was $17.76 \% \pm 2.24 \%$. These data showed that c-Ets1 could inhibit the proliferation of CD $34^{+}$ cells. 

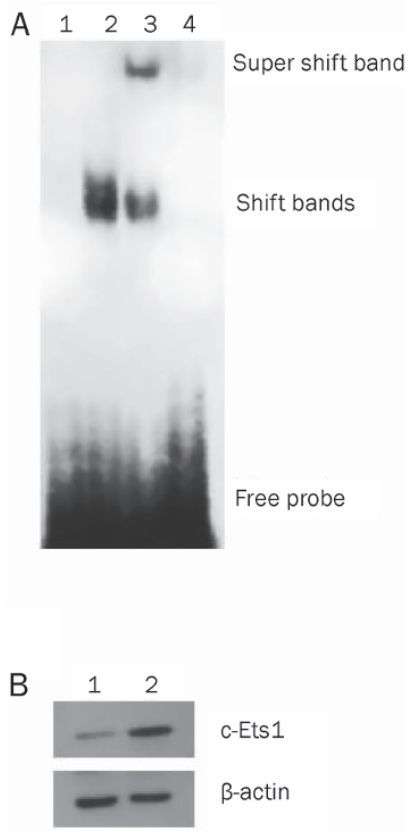

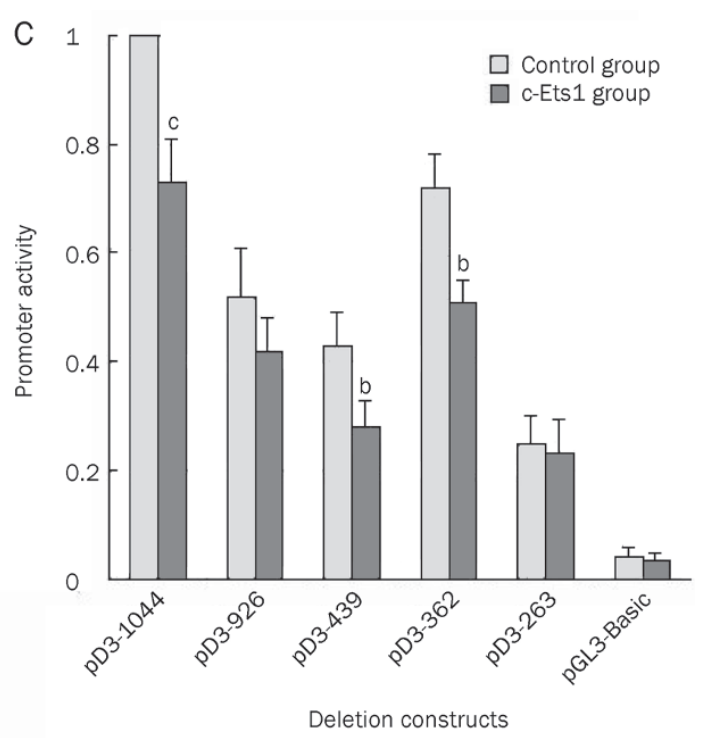

Figure 3. The effects of c-Ets1 on activity of cyclin D3 promoter. EMSA and Super shift assay detected C-Ets1 in CD $34^{+}$ cells. lane 1 , free probe; lane 2, nuclear extract+labeled probe; lane 3, nuclear extract+labeled probe+antibody; lane 4, nuclear extract+labeled probe+cold probe. (B) $\mathrm{CD}_{4}{ }^{+}$cells transfected with pSG5-Ets1 (lane 2 ) or vector alone (lane 1 ) were collected after $36 \mathrm{~h}$ incubation. Western blot was applied to detect the expression of c-Ets1 in $\mathrm{CD} 34^{+}$cells transfected with pSG5-Ets1 cells. (C) CD34 cells were co-transfected with the pSG5-Est1 (or pSG5) and the promoter deletion constructs pD3-1044, pD3-926, pD3-439, pD3-362, pD3-263 or pGL3-Basic respectively. Dual Luciferase assay system was used to determine the effects of $\mathrm{c}-\mathrm{Ets} 1$ on the cyclin D3 promoter activity. $n=6$. Mean \pm SD. ${ }^{b} P<0.05,{ }^{c} P<0.01$ vs control.
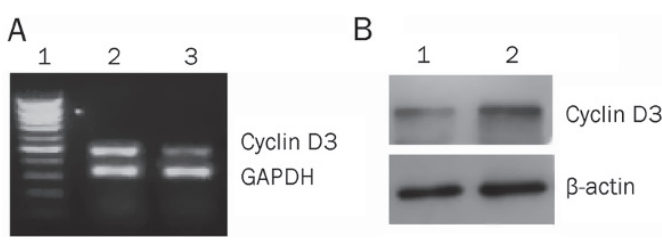

Figure 4. The effects of c-Ets1 on cyclin D3 expression. (A) CD $34^{+}$cells were transfected with pSG5-Est1 or pSG5 vector and cyclin D3 mRNA expression was determined using semi-quantitative RT-PCR. Lane 1, marker; lane 2, pSG5 vector (control) group; lane 3, pSG5-Est1 group. (B) After CD34+cells were transfected with pSG5-Est1 or pSG5 vector, cyclin D3 protein was determined by Western blot. Lane 1, pSG5-Est1 group; lane 2, pSG5 vector (control) group.

\section{Discussion}

The initiation of cell cycle progression is crucial to the differentiation and proliferation of HSCs. Especially important is the $G_{1}$ phase, as extracellular signals during this interval may signal cells to commit to progression to the next phase. Cyclin $\mathrm{D}$ proteins, which are expressed before cyclin $\mathrm{E}$ at the initial stage of the cell cycle, are essential $\mathrm{G}_{1}$-phase regulators. With the stimulation of mitogenic signals (such as growth factors), HSCs synthesize cyclin D proteins, which form a complex with CDK4 and CDK6, leading to the phosphorylation of Rb protein and the successive activation of downstream genes. In this way, cells pass the $G_{1} / S$ checkpoint and enter the $S$ phase. Once this checkpoint is overridden, cells can progress through the whole cell cycle, even in the absence of growth factors ${ }^{[2,12]}$.

At present, three isoforms of cyclin D have been identified that display tissue-specific expression patterns. Cyclin D3 is a dominant regulator in HSCs and is regulated mainly at the transcriptional level ${ }^{[3,5]}$. Transcription factors bind to the promoter region of cyclin D3 and regulate the activity of promoters and, thus, the transcription of the target gene. Both positive and negative regulatory elements are involved in the modulation of cyclin D3 transcription ${ }^{[6]}$. To date, most studies concerning cyclin D3 transcription have focused on the positive regulators, with few reports discussing negative regulators.

To explore the mechanism underlying cyclin D3 transcription regulation, we cloned promoter deletion sequences, transfecting them into CD $34^{+}$cells after short-term expansion. The CD34 antigen is a generally accepted marker of human HSCs and early progenitor cells. The amount of CD $34^{+}$cells after short term expansion was more than $60 \%$, indicating that more than half of the expanded cells retained their stem and progenitor cell characteristics. Furthermore, most of the expanded cells were in the cell cycle and could be transfected easily. As a result, we discovered a negative regulatory region between $-439 \mathrm{bp}$ and $-361 \mathrm{bp}$ in the promoter of cyclin D3. Further analysis indicated that binding sites of many transcription factors such as USF, c-Ets1, HNF-3b, N-Myc and Lyf- 1 were also present in this region. USF is a positive transcription factor and can up-regulate the activity of various promoters $^{[15]}$. Additionally, HNF-3b is expressed mainly in liver and is responsible for the modulation of genes involved in glucose and lipid metabolism during hepatocyte differentiation $^{[16]}$. Some laboratories have demonstrated that N-Myc is a positive transcriptional regulator and involved in carcinogenesis, especially in the nervous system ${ }^{[17]}$. Lyf-1 is expressed in lymphoid cells and involved in the transcription of some lymphoid-specific genes ${ }^{[18]}$. The transcription factor c-Ets1 is expressed in HSCs and the megakaryocytic, myeloid and lymphoid lineages, where it plays a crucial role in differentiation and proliferation ${ }^{[8-12]}$. Based on all this evidence, we speculated that c-Ets1 was probably a negative transcription factor 
for cyclin D3 transcription.

Utilizing EMSA and super shift assays, we found that c-Ets1 was expressed in the nucleus of $\mathrm{CD} 34^{+}$cells and that it bound to the negative regulatory domain of the cyclin D3 promoter. Transient expression of c-Ets1 in $\mathrm{CD} 34^{+}$cells suppressed promoter activity, decreased the mRNA and protein level of cyclin D3, and inhibited the proliferation of $\mathrm{CD} 34^{+}$cells. Our results indicate that c-Ets1 can repress cyclin D3 promoter activity and is thus a negative regulator of cyclin D3.

The Ets protein family is one of the largest signal-dependent transcription factor families. Ets1, present on human chromosome 11q23 and encoding a $54 \mathrm{kDa}$ protein, is a widely expressed transcription factor implicated in cell proliferation, differentiation and apoptosis, but its role varies depending on cell type and differentiation stage ${ }^{[7-12]}$. Our results demonstrate that c-Ets1 is expressed in CD $34^{+}$cells and specifically binds to the cyclin D3 promoter. Furthermore, c-Ets1 inhibits cyclin D3 activity, consequently decreasing its transcription and expression. Because cyclin D3 plays a key role in modulating the proliferation of $\mathrm{CD} 34^{+}$cells, c-Ets1 is a potential target for inhibiting the growth of $\mathrm{CD} 34^{+}$cells. Our results help in clarifying the mechanism underlying hematopoietic diseases, providing possible targets for clinical treatments.

\section{Acknowledgements}

This work was supported by the National Natural Science Foundation of China (№ 30070326).

\section{Author contribution}

Jian-feng ZHOU, Han-ying SUN and Wen-li LIU designed the research; Fan-kai MENG, Xi-you TAN and Chun-rui LI performed the research; Fan-kai MENG and Xi-you TAN analyzed the data; and Fan-kai MENG and Han-ying SUN wrote the paper.

\section{References}

1 Jude CD, Gaudet JJ, Speck NA, Ernst P. Leukemia and hematopoietic stem cells: balancing proliferation and quiescence. Cell Cycle 2008; 7 : 586-91.

2 Della Ragione F, Borriello A, Mastropietro S, Della Pietra V, Monno $\mathrm{F}$, Gabutti $\mathrm{V}$, et al. Expression of $\mathrm{G}_{1}$-phase cell cycle genes during hematopoietic lineage. Biochem Biophys Res Commun 1997; 231: 73-6.
3 Ma Y, Yuan J, Huang M, Jove R, Cress WD. Regulation of the cyclin D3 promoter by E2F1. J Biol Chem 2003; 278: 16770-6.

4 Masamha CP, Benbrook DM. Cyclin D1 degradation is sufficient to induce $\mathrm{G}_{1}$ cell cycle arrest despite constitutive expression of cyclin E2 in ovarian cancer cells. Cancer Res 2009; 69: 6565-72.

5 Kozar K, Ciemerych MA, Rebel VI, Shigematsu H, Zagozdzon A, Sicinska E, et al. Mouse development and cell proliferation in the absence of $D$-cyclins. Cell 2004; 118: 477-91.

6 Ando K, Ajchenbaum-Cymbalista F, Griffin JD. Regulation of $G_{1} / S$ transition by cyclins D2 and D3 in hematopoietic cells. Proc Natl Acad Sci U S A 1993; 90: 9571-5.

7 Dittmer J. The biology of the Ets1 proto-oncogene. Mol Cancer 2003; 2: 29.

8 Eyquem S, Chemin K, Fasseu M, Chopin M, Sigaux F, Cumano A, et al. The development of early and mature $B$ cells is impaired in mice deficient for the Ets-1 transcription factor. Eur J Immunol 2004; 34: 3187-96.

9 Jackers P, Szalai G, Moussa O, Watson DK. Ets-dependent regulation of target gene expression during megakaryopoiesis. J Biol Chem 2004; 279: 52183-90.

10 Marziali G, Perrotti E, Ilari R, Lulli V, Coccia EM, Mazzeo S. Role of Ets1 in erythroid differentiation. Blood Cells Mol Dis 2002; 29: 553-61.

11 Lulli V, Romania P, Riccioni R, Boe A, Lo-Coco F, Testa U, et al. Transcriptional silencing of the ETS1 oncogene contributes to human granulocytic differentiation. Haematologica 2010; 95: 1633-41.

12 Lulli V, Romania P, Morsilli O, Gabbianelli M, Pagliuca A, Mazzeo S, et al. Overexpression of Ets-1 in human hematopoietic progenitor cells blocks erythroid and promotes megakaryocytic differentiation. Cell Death Differ 2006; 13: 1064-74.

13 Lee MW, Jang IK, Yoo KH, Sung KW, Koo HH. Stem and progenitor cells in human umbilical cord blood. Int J Hematol 2010; 92: 45-51.

14 Kast C, Wang M, Whiteway M. The ERK/MAPK pathway regulates the activity of the human tissue factor pathway inhibitor-2 promoter. J Biol Chem 2003; 278: 6787-94.

15 Makaula S, Adam T, Essop MF. Upstream stimulatory factor 1 transactivates the human gene promoter of the cardiac isoform of acetyl-CoA carboxylase. Arch Biochem Biophys 2006; 446: 91-100.

16 Kanda S, Shiroi A, Ouji Y, Birumachi J, Ueda S, Fukui H, et al. In vitro differentiation of hepatocyte-like cells from embryonic stem cells promoted by gene transfer of hepatocyte nuclear factor 3 beta. Hepatol Res 2003; 26: 225-31.

17 Nesbit CE, Tersak JM, Prochownik EV. MYC oncogenes and human neoplastic disease. Oncogene 1999; 18: 3004-16.

18 Hahm K, Ernst P, Lo K, Kim GS, Turck C, Smale ST. The lymphoid transcription factor LyF-1 is encoded by specific, alternatively spliced mRNAs derived from the Ikaros gene. Mol Cell Biol 1994; 14: 711123. 